\title{
Ileum Cavernous Hemangioma, Diagnostic and Therapeutic constraint
}

Auteurs: HATRI.F; YAZI.AE; BOUANANI.I; DASSI.K; RAHMOUNI.FZ; HANNOU.M Service de chirurgie pédiatrique CHU Sidi Bel Abbés / Algérie

\section{Introduction:}

It is a vascular malformation of capillary, cavernous or mixed type, also called telangiectasia or angiodysplasia.

The intestinal localization is rare especially ileal which comes in 3rd position after the rectum and the colon. Digestive hemorrhage (rectorrhagia) is the main symptom.

\section{Observation :}

Child aged 06 years hospitalized for rectorragies of average abundance with several episodes going back to 03 months. Clinical anemia,

Surgical treatment: Median Laparotomy

Exploration ileum bluish mass of $08 \mathrm{~cm}$ long at $40 \mathrm{~cm}$ from the iléo caecal junction at the level of the anti mesenteric edge whose macroscopic appearance is that of an angiomatous tumor. Phlegmonous appearance appendage

An intestinal resection of $10 \mathrm{~cm}$ is carried out, carrying the angioma completed by an ilo-ileal termino-terminal anastomosis and appendectomy.

Operative part addressed to the histological study. The result was cavernous angioma of the muscularis.

Positive operative follow-up and evolution after a decline of 03 months:no rectorragia $(\mathrm{Hg}=11 \mathrm{~g} / \mathrm{dl})$

\section{Discussion:}

The intestinal hemangioma is rare, it is a vascular malformation reported in 1839, granting the embryonic origin. They are lesion of sequestration of mesoderm. The literature reports 200 cases, the incidence is estimated at 1/14000 patient.Tm benign Tm of the gastrointestinal tract from the ileum Several classification described:

- Histological: Capillary, Cavernous, Mixed

Moore's classification based on the seat and type of components (arterial, venous, lymphatic),

- Other: Infant hemangioma and Congenital may be part of genetic syndromes such as (Blue rubber bleb Naevius, Klippel-Trenaunay syndrome),
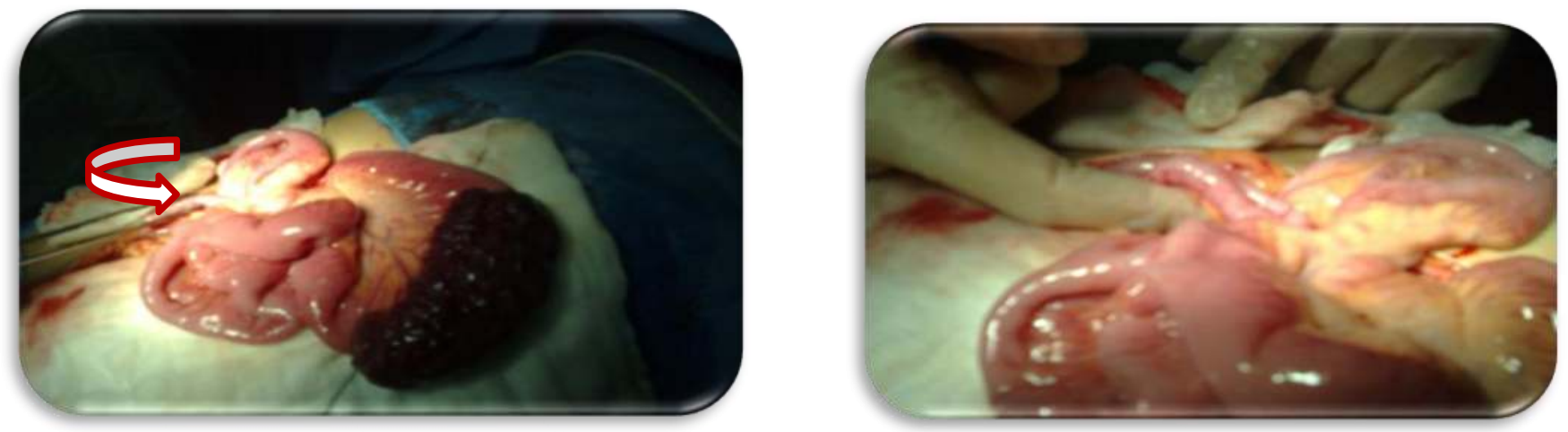

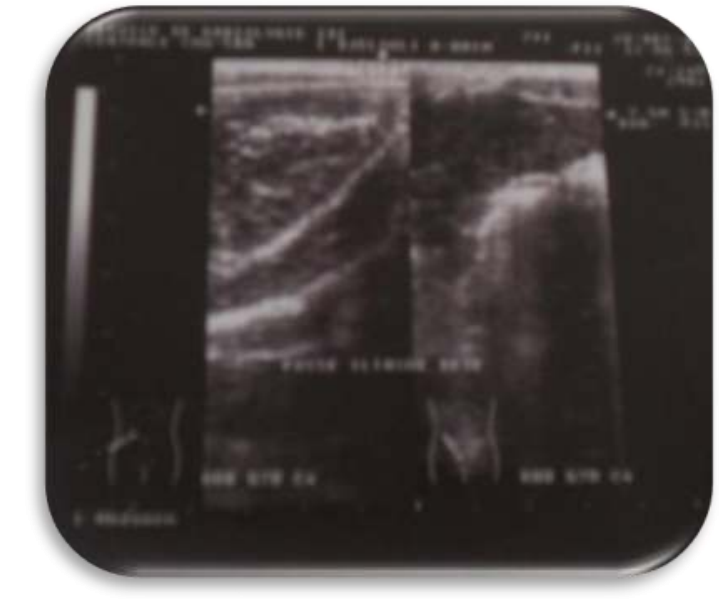

Abdominal and pelvic echography: vascular ectasia localized on a digestive loop

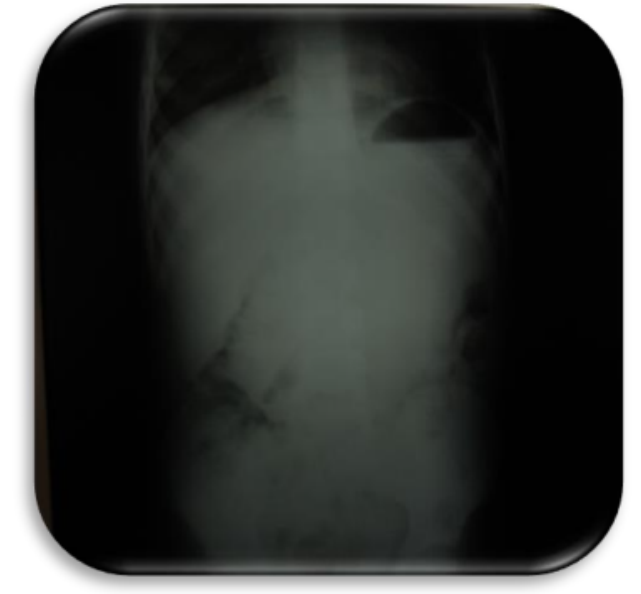

ASP: Frozen clarity at the level of the right iliac fossa
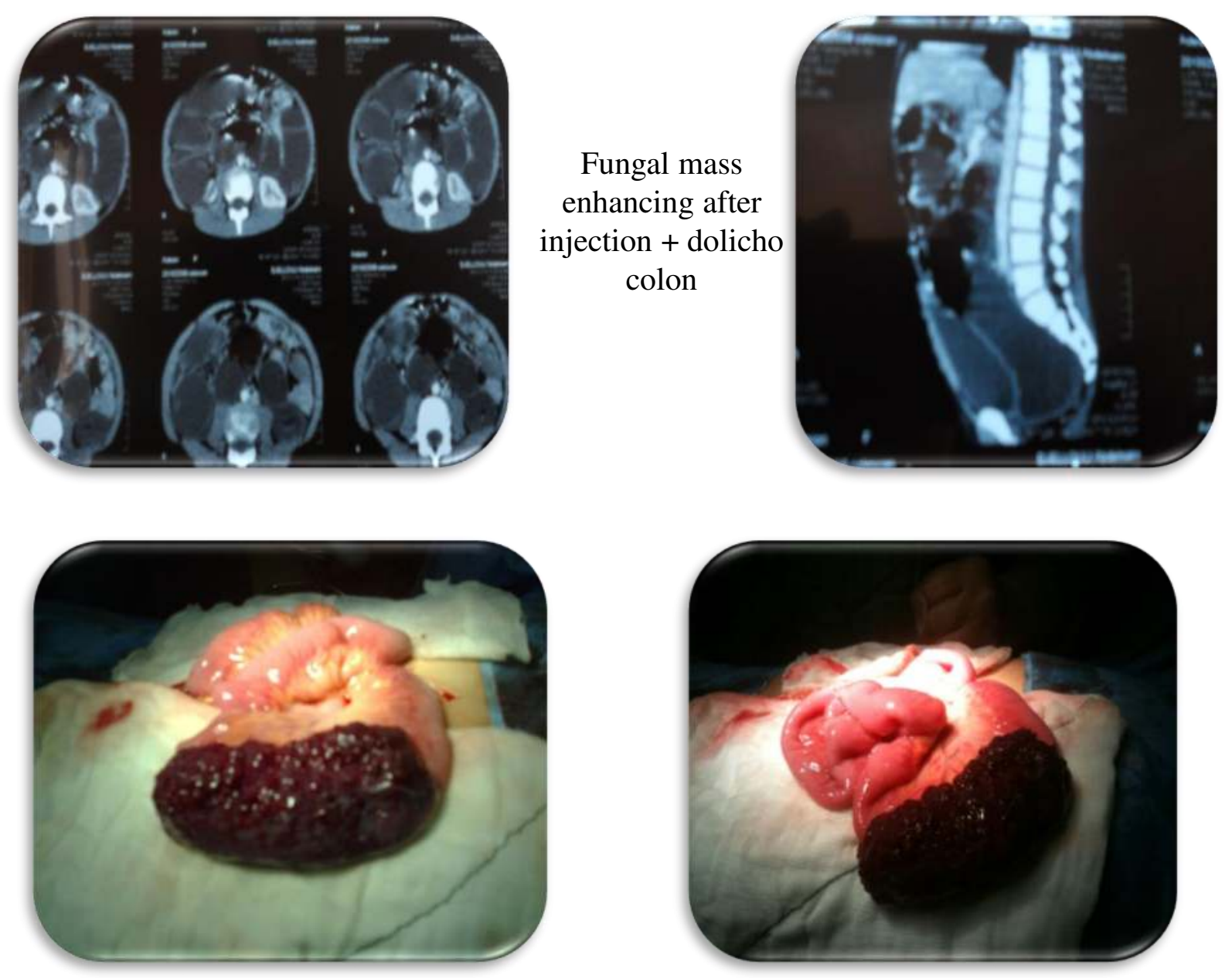

Resection of Tumor with ileo ileal end to terminal anastomosis and appendectomy

Histology: encompasses dilated vascular cavities lined by thick walled endothelial lining.

Manifested by bleeding 60 to $90 \%$,Asymptomatic 10\%,

Currently the entero scopie pushed either the video-endoscopic

capsule are of great interest (70 to $85 \%$ )

others propose embolization following selective angiography.

\section{Conclusion}

Responsible for over $70 \%$ of life-threatening digestive hemorrhage.

Diagnosis still difficult despite advances in imaging

The therapeutic approach depends on the amount and repetition of bleeding episodes.

appendectomy
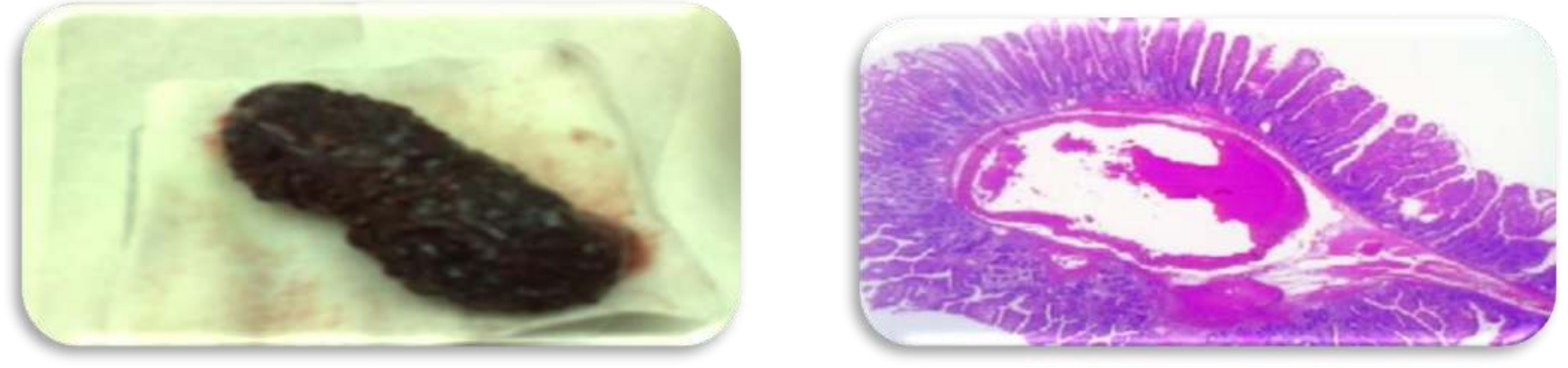

Microscopic aspect (dilated vascular cavities + parietal thickening

\section{Références}

Bendahou.A- Jalal. H - Essadik.O - Oushal. AT Radiology santemaghreb June2005 Radiology santemaghreb.June2005
. Boudiaf et al, smal diseases.prospective.Radiology 2004, 233.338-344 Boyle. L, Lack.EE; Solitary cavernous of smal internally. Arch Pathol Lab Med 1993; 117; $939-41$ . K. Vahedi et al: Seminaire DES2007 = endoscopic exploration of the small bowel . Romania.PS et al; Hemangioma of Small Intestine AmJ Gastroenterol 1995; 90: 2063-4 . Sylle.P; Deutsch.G; Luoj.R. Rare cause of rectal bleeding- case series and review of literature 